\title{
CONTROLE JURISDICIONAL DOS INTERNA CORPORIS ACTA NO DIREITO ESPANHOL
}

\author{
Ana Maria D'Ávila Lopes* \\ José Antonio Tirado**
}

RESUMO: A teoria dos interna corporis acta defende que determinados atos do Parlamento não podem ser submetidos ao controle jurisdicional. Essa teoria teve sua origem na Inglaterra em uma época em que era necessário reforçar a instituição do Parlamento perante as ambições absolutistas do monarca. $\mathrm{Na}$ atualidade, questiona-se até que ponto essa teoria pode continuar sendo mantida em um Estado de Direito, no qual nenhum poder está acima da constituição. Como uma forma de ilustrar os questionamentos levantados contra essa teoria, apresenta-se a experiência do Direito espanhol que, por meio do seu Tribunal Constitucional, tem se pronunciado pela sujeição de todos os poderes à constituição e, portanto, ao controle jurisdicional.

PALAVRAS-CHAVE: Parlamento; Interna corporis acta; Direito constitucional espanhol

\section{INTRODUÇÃO}

O surgimento histórico das prerrogativas parlamentares, na sua versão mais moderna, foi conseqüência da necessidade da criação de mecanismos de defesa do Parlamento contra o poder absoluto do soberano.

* Doutora e Mestre em Direito Constitucional pela Universidade Federal de Minas Gerais. Professora do Mestrado em Direito Constitucional da Universidade Federal do Ceará e da Universidade de Fortaleza.

** Professor de Direito Constitucional da Pontificia Universidad Católica del Perú.
Assim, as diversas prerrogativas, que foram atribuídas aos parlamentares, estavam destinadas a preservar a instituição ante os ataques que o monarca absolutista podia efetuar contra eles. Tais prerrogativas decorriam da incipiente consolidação do princípio democrático que, como princípio legitimador do exercício do poder, atribuía ao Parlamento a titularidade da soberania nacional pelo mecanismo da representação política e direta do povo.

$\mathrm{O}$ posterior surgimento dos partidos políticos (e suas correlações na sede legislativa, ou seja, os grupos parlamentares) 
provocou o início da discussão sobre as aparentemente inamovíveis prerrogativas da vida parlamentar. Com efeito, o denominado Estado de Partidos começou a questionar a fundamentação ideológica da forma de atuação dos parlamentares. ${ }^{1}$

A discussão da simples possibilidade de submeter a atividade desenvolvida pelo Parlamento, ou pelos parlamentares no exercício das sus funções, ao controle jurisdicional não tem sido uma constante na história do Direito Constitucional nem, muito menos, uma conquista facilmente alcançada. Nesse sentido, cabe mencionar que o controle jurisdicional da atividade parlamentar tem enfrentado certas objeções teóricas que, generalizadas no passado, ainda subsistem. ${ }^{2}$

1 VEGA, Pedro de. Estado Social y Estado de Partidos: la problemática de la legitimidad. In: Ius et Veritas. n. 8. Lima: Asociación de Estudiantes de la Pontificia Universidad Católica del Perú, 1994. p.137-140.

2 "A estas alturas no es preciso insistir en la supremacía formal y material de la Constitución. No obstante, conviene recordarla pues, aunque cada vez en menor medida, todavía no se han abandonado totalmente algunas ideas y postulados procedentes de otros tiempos en los que ni se había afianzado la noción de la Constitución como norma jurídica vinculante para todos, ni el parlamento se hallaba por ese y otros motivos plenamente sometido a ella como ocurre en la actualidad. En efecto, algunos fantasmas del pasado, en su tiempo útiles para consolidar la posición de las cámaras, aparecen de vez en cuando para reinvindicar espacios de libre decisión, no vinculada, para ciertos acuerdos parlamentarios. Me refiero al viejo dogma de la soberanía parlamentaria, a las reinvindicaciones enfáticas de la independencia de las Cámaras, en cuanto postulado derivado del principio de la división de poderes, o a la doctrina de los interna corporis acta. En efecto, si en otros tiempos se esgrimieron para rechazar toda fiscalización externa sobre los actos parlamentarios - legislativos o no
No presente estudo, apresentar-se-á as principais objeções que têm sido realizadas a respeito da isenção do controle jurisdicional da atividade parlamentar. Dessa forma, em primeiro lugar, será desenvolvida a teoria dos interna corporis acta para, seguidamente, analisar algumas das mais importantes decisões do Tribunal Constitucional espanhol, dada a significativa jurisprudência que sobre o tema tem elaborado, permitindo apreciar como essa teoria vem sendo aplicada em um ordenamento jurídico moderno, que reconhece a sujeição de todos os poderes constituídos à constituição.

\section{OS ATOS INTERNOS DAS CÂMARAS (INTERNA CORPORIS ACTA)}

Um adequado entendimento da problemática da isenção do controle jurisdicional da atividade parlamentar requer uma aproximação histórica ao conceito de atos internos, o que permitirá compreender o surgimento do Parlamento, assim como a funcionalidade atribuída a suas instituições.

\subsection{Os internal proceedings do Direito inglês}

A data do surgimento da moderna instituição parlamentar - deixando de lado seus precedentes medievais - deve ser localizada em 1688. Anos antes, a Inglaterra tinha sido testemunha da tentativa de quebrar

\footnotetext{
legislativos -, todavía se puede caer en la tentación de recurrir a ellos en demanda de espacios exentos de control para las asambleas legislativas." (MURILLO DE LA CUEVA, Pablo Lucas. El Estatuto de los parlamentarios. Problemas Generales. In: Parlamento y Derecho. FIGUEROA, Alberto; SILVA. Juan Carlos da (Coord.). Vitoria, 1991. p.59-60.
} 
a forte posição que o Parlamento tinha conseguido através dos séculos. Os reis Carlos I y Jacob II haviam tentado implantar um modelo político fundado no direito divino dos monarcas, a semelhança do que acontecia na Europa continental. Entretanto, as câmaras parlamentares conseguiram evitá-lo ao movimentar exércitos e lutar contra essas pretensões. Assim, em 1688, conseguiram derrotar definitivamente esses esforços monárquicos, impondo uma monarquia hereditária submetida às limitações inicialmente estabelecidas no Bill of Rights de 1689 e, depois, na Establisment Act de $1714 .^{3}$ O Parlamento começava a adotar um lento e progressivo papel protagônico na vida política inglesa, o que se traduziu na teoria da soberania parlamentar $^{4}$ e na consagração da proibição do conhecimento judicial dos internal procedings prevista no Bill of Rights. Proibição que pode ser entendida como a natural reação de um Parlamento que tinha sido objeto de perseguições e que, a partir da sua vitória política, pretendia evitar, no futuro, qualquer tipo de intromissão da monarquia no seu funcionamento. ${ }^{5}$

Por outro lado, o conceito dos internal proceedings tem dado lugar a uma série

\footnotetext{
3 GARCIA PELAYO, Manuel. Derecho Constitucional Comparado. Madri: Alianza Universidad, 1984, p.268-269.

4 TORRES MURO, Ignacio. El control de los actos parlamentarios en Inglaterra. Revista Española de Derecho Constitucional. n.43. Madri: Centro de Estudios Políticos y Constitucionais. 1995. p.53.
}

5 TORRES MURO, I. op. cit. p.58. de pronunciamentos judiciais, ${ }^{6}$ nos quais têm-se debatido o conteúdo e alcance da impossibilidade de sua submissão ao controle jurisdicional. Dentre os mais importantes pronunciamentos que foram realizados sobre essa problemática, podem ser citados aqueles nos quais discutiu-se o alcance das prerrogativas parlamentares e a falta de controle judicial sobre os atos e procedimentos legislativos.

Em relação ao exercício das prerrogativas parlamentares, apresentaram-se, a partir do ano 1836, uma série de processos judiciais por difamação, iniciados por um editor de livros (Stockdale) contra um funcionário da Câmara (Hansard), pela publicação de um relatório parlamentar em que se mencionava que alguns dos livros, publicados por Stockdale, continham ilustrações obscenas e indecentes. Para resolver o caso, o Tribunal teve que inicialmente analisar a existência ou não da prerrogativa parlamentar de publicar relatórios parlamentares. A Câmara dos Comuns argüiu como defesa, a existência dessa prerrogativa e a competência exclusiva da Câmara para analisar o alcance de seus próprios atos. O Tribunal, pelo contrário, afirmou que: “(...) la Cámara de los Comunes no era el único juez de sus prerrogativas, y que no estaba evidentemente por encima

${ }^{6}$ Em 1704, o Chief Justicie Holt, um dos mais altos cargos na judicatura inglesa, afirmou que: “cuando la Cámara de los Comunes sobrepasa los límites legales y su autoridad, sus actos son injustos y no se pueden justificar más que los actos de personas privadas: no hay duda que su autoridad proviene del derecho, y al estar limitada, por ello puede ser sobre pasada”. Apud. TORRES MURO, Ignacio. op. cit. p.60. 
de la ley".7 Desse modo, após uma série de conflitos entre o Parlamento e os tribunais, editou-se em 1840 o Parliamentary Papers Act que protegia os documentos parlamentares publicados, visto considerar que as prerrogativas parlamentares abrangiam todas publicações realizadas nas câmaras e dando solução, dessa maneira, à situação apresentada.

Com relação ao controle judicial sobre os atos parlamentares, surgiu um importante caso a propósito da sanção imposta a um membro do Parlamento inglês por se negar a jurar fidelidade à Coroa. Quando foi apresentado esse caso perante os tribunais, estes evitaram pronunciar-se sobre o mesmo, afirmando que o que acontecia no interior do Parlamento era de exclusiva competência dele, sem que seja possível, por parte do Judiciário, emitir pronunciamento algum. ${ }^{8}$

O controle sobre o procedimento legislativo também tem sido motivo de pronunciamento por parte da justiça inglesa que, a pesar de algumas manifestações que no seu momento poderiam ter dado a entender a existência de um controle sobre a validade formal de uma lei, tem mantido uma posição unânime (que ainda hoje persiste) no sentido de não admitir tal controle. ${ }^{9}$

Diferentemente, os funcionários das câmaras inglesas sim se encontram submetidos ao poder dos órgãos jurisdicionais. Assim, em 1978 foram modificadas as normas de proteção dos funcionários, nas quais foi expressamente estabelecido que nenhuma

\footnotetext{
7 TORRES MURO, I. op. cit. p.61.

8 Ibid. p.63.

9 Ibid. p.69.
}

prática ou norma parlamentar poderia impedir que um empregado do Parlamento pudesse recorrer aos tribunais para a proteção de seus direitos. De qualquer forma, cabe salientar que, antes dessa modificação, as câmaras nunca tinham invocado suas prerrogativas como forma de se isentar da análise jurisdicional ${ }^{10}$ em processos de caráter trabalhista, iniciados por algum dos seus funcionários.

Aprecia-se, assim, a possibilidade de submeter a controle jurisdicional a atividade parlamentar na Inglaterra encontra-se submetida a severas restrições que, devemse ter presente, fundamentam-se basicamente na própria natureza das instituições inglesas, onde não existe uma constituição rígida e cujo conceito de soberania parlamentar - e a peculiar composição de seu sistema judicial $^{11}$ - fazem praticamente impossível tal controle.

\subsection{A teoria dos interna corporis acta}

Em 1863, a experiência inglesa seria seguida pela Alemanha para explicar e justificar a existência dos chamados interna corporis acta. O jurista alemã Rudolf Von Gneist afirmou, nessa oportunidade, que um juiz somente podia analisar a validade formal de uma lei em relação à:

“(...) aquellas fases del procedimiento legislativo con relevancia ad extra... Por el contrario, aquellas fases del procedimiento

10 TORRES MURO, Ignacio. loc. cit.

${ }^{11}$ É importante lembrar a existência do exercício de certas atribuições judiciais por parte das câmaras legislativas. (TORRES MURO, Ignacio. op. cit. p.55-56). 
legislativo que se desarrollen completamente al interior del Parlamento y que carezcan de relevancia externa, no podían ser objeto de control jurisdiccional alguno". ${ }^{12}$

Alguns autores têm afirmado a existência de dois conceitos de interna corporis acta: a) restritivo, limitado àquelas fases do procedimento legislativo que se desenvolvem exclusivamente no interior do Parlamento; b) amplo, que inclui, dentro do conceito de interna corporis acta, toda atuação parlamentar derivada de sua autonomia administrativa $^{13} \mathrm{e}$, inclusive, outros âmbitos de atuação das câmaras parlamentares. ${ }^{14}$

O contexto político, no qual formulouse a teoria dos interna corporis acta, foi também considerado elemento-chave para entender a sua incorporação no direito alemão. Assim:

"La finalidad última defendida por Gneist, liberal convencido, era sin duda defender (en un sistema constitucional dominado por el principio monárquico, de suerte que el único poder independiente de la Corona era el Parlamento) la independencia e integridad de atribuciones de la institución parlamentaria". ${ }^{15}$

12 DIEZ PICAZO, Luis María. La autonomía administrativa de las cámaras parlamentarias. Cuadernos de los Studia Albornotiana. Zaragoza, 1985. p.42.

13 DIEZ-PICAZO, Luis María. op. cit. p.40-41.

14 TORRES MURO, Ignacio. El control jurisdiccional de los actos parlamentarios: la experiencia italiana. Revista Española de Derecho Constitucional. n.17. Madrid: Centro de Estudios Políticos y Constitucionales 1986, p.194.

15 TORRES MURO, Ignacio. Actos internos de las Cámaras y recurso de amparo. Un comentario al auto del Tribunal Constitucional de 21 de marzo de 1984. Revista Española de Derecho Constitucional. n.11. Madrid: Centro de Estudios Políticos y Constitucionales, 1984, p.163-161.
É necessário salientar que, ao igual que seu antecedente inglês, os interna corporis acta de formulação alemã, são o resultado de uma luta da instituição parlamentar para sobreviver no interior de um complexo político (e ideológico) contrário a sua existência. Por outro lado, a idéia de soberania parlamentar, que surgiu após Revolução Francesa, contribuirá para afirmar a importância da instituição parlamentar.

\subsection{A autonomia parlamentar no moderno Estado de Direito}

A teoria da existência de determinados atos parlamentares, que gozam de um regime de imunidade jurisdicional, surgiu em um contexto político determinado pela inestabilidade da instituição parlamentar, agravada pelo permanente conflito existente entre o parlamento e os outros centros de poder, especialmente, os monarcas com pretensões de Governo absoluto. Se foi isso que condicionou a origem histórica dessa imunidade jurisdicional, tal situação deve servir, atualmente, para questionar a subsistência do fundamento teórico de tal imunidade.

Destarte, cabe afirmar que as vozes que propugnavam um grau maior ou menor de imunidade jurisdicional do Parlamento não se remontam apenas às origens da teoria dos interna corporis acta, mas atualmente ainda é possível encontrar destacados e autorizados juristas que propõem tais teses, como Fernando Santaolalla.

Esse autor baseia sua posição de que o Parlamento encontra-se dotado de uma supremacia jurídico-política devido a que: 
“(...) está situado en el escalón más alto de la organización estatal. Sus decisiones son reyes y vinculan a todos los órganos del Estado y a los ciudadanos. El, en cambio, sólo tiene como límites ineludibles lo dispuesto por la Constitución, pues, aunque es cierto que el Derecho Parlamentario se integra por una pluralidad de fuentes normativas, todas ellas observables, no lo es menos que el Parlamento goza de un poder de disposición sobre ellas, al estar legitimado para crear, modificar y derogar todo el ordenamiento inferior a la Constitución (....)." ${ }^{16}$

Uma apreciação como a mencionada deve ser, sem dúvida, rejeitada na atualidade. Como questão prévia, deve-se mencionar que, embora seja verdade que o Parlamento tem a capacidade de inovar o ordenamento jurídico, não significa que tem a competência de incumprir uma lei. ${ }^{17}$ Contudo, a perspectiva que melhor ilustra a submissão da atuação parlamentar à Constituição e a lei (e, conseqüentemente, sua sujeição ao controle jurisdicional) é a moderna idéia de soberania popular.

No moderno Estado de Direito o poder soberano do povo manifesta-se na Constituição, expressão máxima de soberania e perante à qual o Parlamento deve assumir a posição de poder constituído (e, por tanto, vinculado) ao igual que o Executivo ou o Judiciário. O princípio da supremacia constitucional determina que, não apenas todas as normas

16 SANTAOLALLA LOPEZ, F. op. cit. p.30.

17 Nesse sentido pronuncia-se Gómez-Ferrer: “El legislador puede cambiar las leyes, dentro del marco de la Constitución, pero lo que no puede es dejar de observarlas en sus actuaciones sin valor de ley." (GOMEZ-FERRER MORANT, Rafael. Derecho a la tutela judicial y posición jurídica peculiar de los poderes públicos. Revista Española de Derecho Administrativo. n.33. Madrid: Civitas, p.205). infraconstitucionais, mas também todos os órgãos por ela configurados, reconhecem-se como subordinados às previsões ali contidas. Por tanto, não existe uma relação de superioridade do Parlamento ante os outros órgãos constitucionais, nem muito menos, ante à Constituição. ${ }^{18}$

A autonomia parlamentar foi entendida originariamente como um requisito para a subsistência das câmaras parlamentares ante os perigos que representava a $\operatorname{Coroa}^{19} \mathrm{em}$ momentos em que, como antes mencionado,

18 “(...) si se parte de la idea de la soberanía popular o, si se quiere, de la idea de poder constituyente, para subrayar el carácter germinal, no sólo en el tiempo, que es lo menos, sino sobre todo en orden lógico, de este poder, la incardinación en la Constitución de los derechos ciudadanos, y de los deberes del poder, o lo que es lo mismo, la afirmación de la Constitución como fuente del Derecho, adquiere una firmeza granítica. La consideración del pueblo como titular único de la soberanía fuerza, como es obvio, a atribuirle el poder constituyente. De la Constitución, que es su obra, derivan todas las instancias concretas del poder que son, por ello, poderes constituídos. No sólo se trata ya de que el haz de facultades que cada uno de ellos puede desplegar esté pre-constituído, sea limitado sino que, y esto es lo fundamental, de que esta limitación no resulta un acto libre de esas instancias concretas de poder o del Estado, del que son órganos, sino de la relación de dependencia en que esos órganos se encuentran respecto del pueblo. Esta dependencia no puede ser asegurada si el pueblo no se reserva para sí, esto es, para cada uno de los individuos que lo integran, un repertorio de derechos, un ámbito de libertad que haga posible el ejercicio real de ese control, y no estructura el poder de manera que el control tenga probabilidades de eficacia”. (RUBIO LLORENTE, Francisco. La Constitución como fuente de Derecho. In: La forma del poder. Madrid: Centro de Estudios Constitucionales, 1993. p.85.

19 TORRES DEL MORAL, Antonio. Artículo 72.1. La autonomía de las cámaras y los estatutos parlamentarios. In: Comentarios a las Leyes Políticas. T. VI. ALZAGA VILLAMIL, Oscar (Dir.). Madrid: Edersa, 1989, p.396. 
vigorava uma monarquia absoluta. Não obstante, na atualidade, tal situação não mais se apresenta e, pelo contrário, a explicação sobre a autonomia parlamentar requer de outra fundamentação. Levando em consideração a importância das funções que constitucionalmente têm sido outorgadas ao Parlamento, ${ }^{20}$ a necessidade de assegurar-lhe um âmbito de autonomia ante o Poder Executivo e demais órgãos constitucionais que permitam o exercício dessas funções com um grau suficiente de independência constitui uma exigência fundamental para conferir condições mínimas necessárias ao Parlamento para o cumprimento de tais funções.

Deve-se salientar que essa situação, qualificada como fundamental, é especialmente relevante se se adverte que, na maioria dos países da América do Sul, não estamos ante regimes parlamentares (onde a conformação do Governo é conseqüência da determinação das maiorias e minorias parlamentares) mas que, tanto o Governo como o Parlamento são eleitos diretamente, apresentando-se, com maior facilidade, uma situação na qual o Governo não tenha maioria ou respaldo parlamentar, situação em que as funções ou atribuições parlamentares poderão ser muito amplas.

A mudança das circunstâncias históricas exige, sem dúvida, que as soluções dadas a certos problemas devam ser revisadas à luz das atuais circunstâncias. A superação da situação de conflito entre o Governo e o Parlamento mediante o reconhecimento

${ }^{20}$ La producción legislativa y el control del gobierno. (Cf. DIEZ-PICAZO. Luis María. op. cit. p.29 e ss.). constitucional de ambos como órgãos constitucionais - sujeitos como tais à Constituição -, a idéia de soberania popular e o caráter normativo da Constituição como expressão máxima dessa, questionam a autonomia parlamentar e a teoria dos interna corporis acta, colocando sérios desafios que não sempre têm sido coerentes com a mudança das circunstâncias históricas mencionadas.

\section{O CONTROLE DOS INTERNA CORPORIS ACTA NA TEORIA DO TRIBUNAL CONSTITUCIONAL ESPANHOL}

Após análise realizada anteriormente, considera-se oportuno fazer referência ao tratamento que os interna corporis acta têm recebido por parte do Tribunal Constitucional espanhol dada a significativa jurisprudência que sobre o tema tem elaborado.

\subsection{Decisão do Tribunal Constitucional de 21 de março de 1984}

A primeira oportunidade na qual o Tribunal Constitucional teve a opção de se pronunciar em relação à teoria dos interna corporis acta foi em 1984, quando impetrou-se, perante ele, um recurso de amparo $^{21}$ proposto por um senador contra

21 Lei n.o 2/1979 (Lei Orgânica do Tribunal Constitucional espanhol). "Artículo 42". Las decisiones o actos sin valor de Ley, emanados de las Cortes o de cualquiera de sus órganos, o de las Asambleas legislativas de las Comunidades autónomas, o de sus órganos, que violen los derechos y libertades susceptibles de amparo constitucional, podrán ser recurridos dentro del plazo de tres meses desde que, con arreglo a las normas internas de las Cámaras o Asambleas, sean firmes." 
uma decisão da Presidência do Senado, que pretendia regular uma lacuna do Regulamento Interno, referente às potestades da Presidência na organização dos debates parlamentares. $^{22}$

O senador impetrante afirmou que essa nova regulação do Regimento violava seu direito à igualdade perante a lei e ao acesso e exercício de um cargo ou função pública, visto que conferia ao presidente do Senado como diretor dos debates parlamentares - a competência de agrupar as emendas propostas a projetos de lei, submetendo-as a votação conjunta, o qual impedia que os proponentes dessas emendas pudessem defendê-las de forma individual, vinculando a aprovação de umas com a aprovação das outras.

O Tribunal Constitucional indeferiu o recurso e o declarou inadmissível por duas razões:

a) a primeira razão argumentada pelo Tribunal foi sua incompetência para a apreciação dessa matéria, incompetência decorrente da simples leitura do artigo $42^{\circ}$ da sua Lei Orgânica. As alegações do Tribunal foram:

“(...) el primer obstáculo infranqueable para la admisión del presente recurso, pues lo que en él se impugna es una norma y el citado precepto no habla de normas ni de disposiciones, sino sólo de actos o de

${ }^{22}$ Em relação aos fatos e para um maior análise do caso, consultar: TORRES MURO, Ignacio. Actos internos de las Cámaras y recurso de amparo. Un comentario al Auto del Tribunal Constitucional de 21 de marzo de 1984. Revista Española de Derecho Constitucional. n. 11. Madrid: Centro de Estudios Políticos y Constitucionales, 1984. p.153-167. resoluciones, es decir, de decisiones que en la terminología habitual entre nosotros tienen contenido singular, no general." 23

b) a segunda razão esgrimida pelo Tribunal, referia-se à natureza da isenção da apreciação dos interna corporis acta, afirmando o seguinte:

"La norma impugnada es, en efecto, un acto interno de la Cámara, producido por la Presidencia de ésta y que tiene por finalidad la regulación de las relaciones que existen entre la Cámara y sus propios miembros. No es, por tanto, una norma que deba regular las relaciones de la Cámara con terceros vinculados con ella por relaciones contractuales o funcionariales, sino un acto puramente interno de un órgano constitucional. Característica propia de éstos es la independencia y el aseguramiento de ésta obliga a entender que, si bien, sus decisiones, como sujetas que están a la Constitución y a las leyes, no están exentas del control jurisdiccional, sólo quedan sujetas a este control cuando afectan a relaciones externas del órgano (...)" 24

Observe-se que teria sido suficiente que Tribunal Constitucional se limitasse a declarar inadmissível o amparo com base no primeiro dos argumentos, sem ter necessidade de utilizar, ou se referir, aos atos internos das Câmaras.

Qual foi, então, a razão do uso desse segundo argumento? Do conhecimento dos antecedentes do presente caso, pode-se deduzir certo incômodo do Tribunal de ter que ser parte, involuntária certamente, de uma típica disputa parlamentar. Lorenzo Martín Retortillo afirma que:

23 Decisão do Tribunal Constitucional espanhol de 21 de março de 1984.

24 Ibidem 
"este segundo fundamento sirve al Tribunal para, en cierto tono paternal, recordar al Parlamento que los conflictos internos derivados de consideraciones meramente políticas (las enmiendas presentadas tenían una inocultable finalidad obstruccionista) y no es prudente comprometer a tan alto Tribunal en disputas, francamente, menores" 25

Contudo, os fundamentos da decisão comentada, deixam pouco espaço para sustentar que apenas pretendeu-se aquilo e, pelo contrário, constituiu, objetivamente, uma interpretação restritiva do artigo $42^{\circ}$ da sua própria Lei Orgânica, na medida em que, em primeiro lugar, distinguiu onde a lei não tinha feito distinção $\operatorname{alguma}^{26} \mathrm{e}$, em segundo lugar, afirmou um âmbito de imunidade jurisdicional sem limitação alguma, ou seja, segundo o mencionado pelo Tribunal Constitucional, seria suficiente que um ato das Câmaras fizesse referência à relação existente entre ela e seus membros, para que não possa existir controle jurisdicional sobre aquele.

Com essa decisão do Tribunal Constitucional, ficava estabelecido no Direito espanhol que os interna corporis acta eram atos internos das Câmaras destinados à regulação das relações entre ela e seus membros - posicionamento decorrente da sua necessária independência, rejeitandose qualquer tipo de intromissão dos outros órgãos constitucionais. Apenas os atos que possam ter efeitos nas relações externas do órgão parlamentar poderiam estar submetidos a controle judicial.

25 MARTIN RETORTILLO, Lorenzo. El control por el Tribunal Constitucional de la actividad no legislativa del Parlamento. Revista de Administración Pública. n.107, 1988. p.116.

26 TORRES MURO, Ignacio. op. cit. p.161.

\subsection{Decisão do Tribunal Constitucional 90/1985}

Essa tendência ficaria confirmada, um ano depois, com a STC 90/1985. Trata-se nesta oportunidade, de um recurso de amparo impetrado contra a decisão do Senado de indeferir o suplicatorio ${ }^{27}$ formulado pelo Tribunal Supremo para o processamento penal de um parlamentar.

Naquela ocasião, o Senado tinha-se pronunciado no sentido de que o ato de deferimento ou indeferimento da petição do Tribunal Supremo, para o julgamento de um de seus membros, era um ato de vontade política, reservada assim pelo constituinte ao Parlamento. Perante isso, o Tribunal Constitucional insistiu em dividir as atuações parlamentares em dois tipos: aquelas com relevância externa e as outras meramente internas. ${ }^{28}$

Nesse sentido, a respeito dos atos externos, o Tribunal Constitucional afirmou que qualquer faculdade constitucionalmente outorgada não pode ser excluída da sua submissão à Constituição:

"En virtud de este principio cualquier acto del Parlamento con relevancia jurídica externa, esto es, que afecte a situaciones que excedan del ámbito estrictamente propio del funcionamiento de las Cámaras, queda sujeto, comenzando por los de naturaleza legislativa, no sólo a las normas de procedimiento que en su caso establezca la

27 O "suplicatorio" é a solicitação formulada pelo Tribunal Supremo ao Senado ou ao Congreso dos Deputados, solicitando o levantamiento da imunidade parlmentar de um de seus membros.

${ }^{28}$ Nesse caso, o Tribunal Constitucional não faz referência a atos internos, ainda que a menção de atos com relevância externa, somente será lógica se se considera que existem outros com relevância interna. 
Constitución Española, sino, asimismo, al conjunto de normas materiales que en la propia Constitución se contienen. No puede, por ello, aceptarse que la libertad con que se produce un acto parlamentario con esa relevancia jurídica para terceros llegue a rebasar el marco de tales normas, pues ello, en nuestro Ordenamiento, seria tanto como aceptar la arbitrariedad".

\subsection{Decisão do Tribunal Constitucional 292/1987}

Trata-se este caso do recurso de amparo impetrado pela presumível violação do artigo 23.2 da Constituição Espanhola, ao ter-se produzido a designação dos secretários de uma das câmaras legislativas, com infração ao correspondente Regimento.

O Tribunal Constitucional declarou inadmissível a petição alegando que:

"La organización de los debates y el procedimiento parlamentario es cuestión remitida por la Constitución, como se desprende de su artículo 72, a la regulación y actuación independiente de las Cámaras legislativas y los actos puramente internos que adopten las mismas no podrían ser enjuiciados por este Tribunal, en cuanto presuntamente lesivos de los Reglamentos parlamentarios, sin menoscabar aquella independencia como ya declaró este Tribunal en el Auto de 21 de marzo de 1984. Quiere con ello decirse que, sólo en cuanto lesionen un derecho fundamental reconocido en la Constitución y no por infracción pura y simple de un precepto del Reglamento de la Cámara son recurribles en amparo de tales actos internos, en virtud de lo dispuesto en el artículo 42 del LOTC”.

Essa decisão do Tribunal Constitucional é considerada especialmente importante por duas razões:

a) delimita sua competência em relação ao recurso de amparo constitucional, rejeitando as questões (como prefere denominá-las) de simples legalidade, delegando-as para os outros tribunais;

b) constitui o primeiro pronunciamento do Tribunal Constitucional que, em relação a um ato interno de uma Câmara parlamentar, irá reconhecer a existência de limites constitucionais aos mesmos. Limites estabelecidos pelos direitos fundamentais reconhecidos na norma constitucional. Limites que quando violados tornam os atos internos das Câmaras suscetíveis de controle jurisdicional, conforme corresponde a um Estado de Direito. Constitui, como foi mencionado, uma flexibilização da tradicional posição mantida pelo Tribunal Constitucional ${ }^{29}$ ainda que, talvez, seja melhor qualificá-la de um verdadeiro endurecimento da sua posição, como posteriores pronunciamentos o confirmarão.

\subsection{Decisões do Tribunal Constitucional $118 / 1988$ e $161 / 1988$}

Na Sentença do Tribunal Constitucional 118/1988, o Tribunal Constitucional apreciou recurso de amparo impetrado por 67 deputados (a título individual) alegando a violação do seu direito ao exercício de um cargo público, pela qualificação como matéria reservada (e a conseqüente limitação ao seu acesso) de determinada informação relativa à política exterior e de defesa

29 QUINTANA LOPEZ, Tomás. El control jurisdiccional de las decisiones parlamentarias. In: Estudios sobre la Constitución Española. Homenaje al Profesor Eduardo García de Enterría. Tomo III. MARTIN-RETORTILLO, Sebastián (Coord.). Madrid: Civitas, 1991. p.2080. 
do Governo espanhol, estabelecida pela Presidência do Congresso dos Deputados. Frente aos argumentos dos impetrantes, o TC afirmou que:

“(...) ha de reconocerse que la jurisprudencia constitucional en aras del respeto a la autonomía de las Cámaras en orden a su propio funcionamiento ha llevado a calificar a determinados actos parlamentarios como interna corporis, los cuales por su naturaleza, resultarían excluídos del conocimiento, verificación y control por parte de los tribunales (...) Pero ello no excluye, sin embargo, la posibilidad de examinar si aquellos actos han vulnerado en concreto los derechos fundamentales y libertades públicas (...) La doctrina de los interna corporis acta sólo es aplicable en la medida en que no exista lesión de tales derechos y libertades (...) En cuanto un acto parlamentario afecte a un derecho o libertad susceptible de amparo constitucional, sale o trasciende de la esfera irrevisable propia de los interna corporis acta y corresponde a este Tribunal su examen, pero sólo ello de la virtual lesión de tales derechos o libertades". ${ }^{30}$

Será essa a primeira sentença na qual o Tribunal Constitucional se pronuncie em termos tão radicais, em relação à possibilidade de submeter a controle jurisdicional a atividade parlamentar. Do exposto, pode-se apreciar um uso meramente simbólico da teoria dos interna corporis acta, na medida em que essa, por definição, defendia precisamente o não controle jurisdicional da atividade parlamentar de caráter interno, sendo que a sentença confirmará que é suficiente que um ato parlamentar possa

\footnotetext{
${ }^{30}$ Apud, MONTORO PUERTO, Miguel. Control por la jurisdicción constitucional de los actos no legislativos de las cámaras parlamentarias. In: Actualidad y perspectivas del Derecho Público. Homenaje al Profesor Fernando Garrido Falla. Volumen II. Madrid: Complutense. 1991. p.1091-1092.
}

incidir (não violar ou desconhecer, mas simplesmente gerar efeitos) sobre um direito fundamental, para que o Tribunal Constitucional possa entrar a conhecer o fundo do assunto, descartando dessa forma qualquer pretensão de declaração de inadmissibilidade do recurso de amparo pelo caráter interno do ato impugnado. ${ }^{31}$

A partir dessa sentença, o caráter interno de um ato parlamentar não será suficiente para excluir a competência do Tribunal Constitucional. Teoria essa que será confirmada, meses depois, pela Sentença do Tribunal Constitucional 161/1988 que lembrará que apesar da existência de atos internos, “(...) ello no significa que sean irrevisables por esta jurisdicción constitucional cuando se les imputa haber ocasionado concreta violación de derechos fundamentales y libertades públicas (...)”. ${ }^{32}$

Observe-se que o Tribunal Constitucional tem desenvolvido uma jurisprudência que, nos seus inícios, parecia como restritiva dos direitos fundamentais, ${ }^{33}$ ainda que o

${ }^{31}$ Em termos não muito claros, pronuncia-se no mesmo sentido MONTORO PUERTO, Miguel, op cit. p. 1092 .

32 Apud MONTORO PUERTO, M. op. cit. p.1100.

${ }^{33}$ Ignacio TORRES MURO afirma, em uma nota de rodapé, as consequiências extremas às que poderia chegar o Tribunal Constitucional se mantivesse de forma rigorosa sua inicial posição contida na decisão de 21 de março de 1984, afirmando que: "Llevando el razonamiento hasta el absurdo de acuerdo con la postura adoptada por el Tribunal, no serían recurribles los actos singulares discriminatorios como, por ejemplo, una restricción en el derecho de presentación de enmiendas o en el uso de la palabra por razón de sexo (en una Cámara de mayoría machista) o no admitir a trámite las preguntas por manifiesta fealdad del que la hace (en otra que valore la fotogenia)". In: Actos internos de las Cámaras... op. cit. p.163. 
Tribunal Constitucional tentava negar essa posição. ${ }^{34}$ Progressivamente irá matizando sua postura até conseguir um verdadeiro endurecimento, mudando sua posição original em relação ao controle jurisdicional dos interna corporis acta. Não obstante o Tribunal Constitucional reconheça e respeite a existência da autonomia e independência das Câmaras, não renunciará a exercer o controle constitucional sobre determinados atos. Esse último aspecto, é o que permite sustentar que o conceito de interna corporis acta do Tribunal Constitucional é hoje diferente ao que historicamente tinha ou, em todo caso, trata-se de um desvio do mesmo, ou seja, a perda do conteúdo historicamente atribuído a esse tipo de atos parlamentares.

Se os interna corporis acta são, por definição, não controláveis, o Tribunal Constitucional tem mudado essa visão admitindo ser suficiente que tais atos possam incidir sobre direitos fundamentais, para que seja procedente sua competência de se pronunciar a respeito. ${ }^{35}$

O determinante não será, então, o âmbito de aplicação do ato questionado (se trata de um ato com efeitos internos ou, pelo

34 "Se ha considerado, quizá prematuramente, que la doctrina de este Tribunal Constitucional, relativa a la impugnación de los actos parlamentarios singulares de carácter interno, tiene tonos restrictivos" (STC 23/1990).

35 Como posição já definida, cita-se a sentença do Tribunal Constitucional 23/1990 a que, após fazer um resumo da teoria que tinha estado construindo sobre a matéria, afirmará que perante um ato parlamentar ao que se imputa a violação de um direito constitucional é “(...) hacedero y correcto, constitucionalmente, entrar en el examen del acto al que se reprocha la violación del derecho fundamental que se cita (23.2 CE) para determinar si se da o no esa vulneración". contrário, com relevância para terceiros), mas a possibilidade da sua incidência ilegítima sobre direitos fundamentais. O caráter interno de um ato parlamentar não constituirá, nunca, objeção válida para a isenção de seu controle por parte do Tribunal Constitucional que, dessa maneira, retoma sua preocupação central sobre a proteção dos direitos fundamentais. ${ }^{36}$

\section{CONCLUSÃO}

O controle jurisdicional da atividade parlamentar enfrentou historicamente certas objeções, no sentido de limitar seus alcances sobre determinados atos parlamentares. Essas objeções, baseadas na teoria dos interna corporis acta e no dogma da soberania parlamentar, encontravam-se justificadas em momentos nos quais a instituição parlamentar surgia em oposição à instituição da monarquia absoluta. Nesse sentido, a limitação do controle jurisdicional da atividade parlamentar constituía um mecanismo de defesa do Parlamento frente a uma organização judicial que, sem dúvida, não alcançava níveis significativos de imparcialidade.

Contudo, essas circunstâncias históricas não mais se apresentam no moderno Estado de Direito, onde as restrições ao controle jurisdicional dos atos parlamentares carecem de qualquer justificação. Em primeiro lugar, porque o Parlamento tem deixado de ser uma instituição cuja existência encontra-se ameaçada e, em segundo lugar, porque os

36 "Nada que concierna al ejercicio por los ciudadanos de los derechos que la Constitución les reconoce, podrá considerarse nunca ajeno a este Tribunal." (STC de 17 de julio de 1981). 
princípios fundamentais do Estado de Direito vedam a existência de qualquer âmbito de imunidade jurisdicional.

Exemplo dessa clara mudança de concepção da teoria dos interna corporis acta encontra-se no trabalho jurisprudencial desenvolvido pelo Tribunal Constitucional espanhol. Depois de um momento inicial no qual o Tribunal Constitucional parecia decidido a consagrar em termos tradicionais a teoria dos interna corporis acta, a consideração da superioridade da defesa e proteção dos direitos fundamentais terminou por fundamentar a rejeição do uso automático e irrestrito dessa teoria.

Com efeito, para o Tribunal Constitucional espanhol o caráter interno de um ato parlamentar não é determinante para excluir sua competência. $\mathrm{O}$ decisivo não é o âmbito de aplicação do ato questionado (ou seja, se se trata de um ato com efeitos unicamente internos ou, pelo contrário, com relevância para terceiros), mas a possibilidade da incidência ilegítima desses atos sobre direitos fundamentais, parâmetro de validade e legitimidade de toda atuação no Estado de Direito.

\section{JUDICIAL REVIEW OF INTERNA CORPORIS ACTA IN SPANISH LAW}

ABSTRACT: The Interna Corporis Acta theory sustains that some Parliament's acts are not submitted to judicial review. This theory has its origins in England, at a time when it was necessary to strengthen the Parliament's Institution in front of monarch's absolutism. Today, there are doubts whether that theory should be maintained in a State of Law, where no power is above the constitution. As a way to show the critics against that theory, I present the spanish law experience, whose Constitutional Court has declared that every power is submitted to the constitution and, therefore, to judicial review. KEY-WORDS: Parliament; Interna corporis acta; Constitutional Law of Spain

\section{REFERÊNCIAS}

DIEZ PICAZO, Luis María. La autonomía administrativa de las cámaras parlamentarias. In: Cuadernos de los Studia Albornotiana. Zaragoza, 1985.

GARCIA PELAYO, Manuel. Derecho Constitucional Comparado. Madri: Alianza Universidad, 1984.

GARCÍA LÓPEZ, Eloy. Inmunidad parlamentaria y estado de partidos. Madri: Tecnos, 1989.

GOMEZ-FERRER MORANT, Rafael. Derecho a la tutela judicial y posición jurídica peculiar de los poderes públicos. Revista Española de Derecho Administrativo. n. 33. Madri: Instituto de Estudios Políticos, jan.-mar. 1997.

LANDA ARROYO, César. Derecho Político. Del gobierno y la oposición democrática. Lima: Pontificia Universidad Católica del Perú, 1990.

MARTIN RETORTILLO, Lorenzo. El control por el Tribunal Constitucional de la actividad no legislativa del Parlamento. Revista de Administración Pública. n.107. Madri: Instituto de Estudios Políticos, jan.-fev., 2002.

MONROY GÁLVEZ, Juan. Introducción al Proceso Civil. Tomo I. Bogotá: Temis, 1996 MONTORO PUERTO, Miguel. Control por la jurisdicción constitucional de los actos no legislativos de las cámaras parlamentarias. Actualidad y perspectivas del Derecho Público. Homenaje al Profesor Fernando Garrido Falla. V. II. Madri: Complutense, 1991. 
MURILLO DE LA CUEVA, Pablo Lucas. El Estatuto de los parlamentarios. Problemas Generales. In: Parlamento y Derecho. FIGUEROA, Alberto. SILVA, Juan Carlos da (Coord.). Vitoria, 1991.

MURILLO DE LA CUEVA, Pablo Lucas. El examen de la constitucionalidad de las leyes y la soberanía parlamentaria. Revista de Estudios

Políticos. n.7. Madri: Instituto de Estudios Políticos, 1979.

QUINTANA LOPEZ, Tomás. El control jurisdiccional de las decisiones parlamentarias. In: Estudios sobre la Constitución Española. Homenaje al Profesor Eduardo García de Enterría. Tomo III. La Corona. Las Cortes. Del gobierno y la Administración Pública. Sebastián MARTIN-RETORTILLO (Coord.). Madri:

Civitas, 1991.

RUBIO LLORENTE, Francisco. $\mathrm{La}$ Constitución como fuente de Derecho. La forma del poder. Madri: Centro de Estudios Constitucionales, 1993.

SANTAOLALLA LOPEZ, Fernando. Derecho Parlamentario Español. 2.ed. Madri: Espasa Universidad, 1990.
TORRES DEL MORAL, Antonio. Artículo 72.1. La autonomía de las cámaras y los estatutos parlamentarios. In: Comentarios a las Leyes Políticas. Dirigidas por Oscar ALZAGA VILLAMIL. Tomo VI, Madri: Edersa, 1989.

TORRES MURO, Ignacio. El control de los actos parlamentarios en Inglaterra. Revista Española de Derecho Constitucional. n.43

Madri: Centro de Estudios Políticos y Constitucionais, 1995.

TORRES MURO, Ignacio. El control jurisdiccional de los actos parlamentarios: la experiencia italiana. Revista Española de Derecho Constitucional. n.17. Madri: Centro de Estudios Políticos y Constitucionales, 1986.

TORRES MURO, Ignacio. Actos internos de las Cámaras y recurso de amparo. Un comentario al auto del Tribunal Constitucional de 21 de marzo de 1984. Revista Española de Derecho Constitucional.n.11. Madri: Centro de Estudios Políticos y Constitucionales, 1984.

VEGA, Pedro de. Estado Social y Estado de Partidos: la problemática de la legitimidad. Ius et Veritas. Lima: Asociación de Estudiantes de la Pontificia Universidad Católica del Perú, n.8. 1994. 